\title{
ASPECTOS FÍSICOS E FUNCIONAIS DE UMA UNIDADE DE ALIMENTAÇÃO E NUTRIÇÃO DE UM MUNICÍPIO MARANHENSE
}

Physical and functional aspects of a feeding and nutrition unit of a Maranhense municipal

Aspectos físicos y funcionales de una unidad de alimentación y nutrición de un municipio de Maranhense

Joyce Lopes Macedo $^{* 1}$, Amanda Suellenn da Silva Santos Oliveira ${ }^{2}$, Irislene Costa Pereira ${ }^{2}$, Josiane da Rocha Silva Ferraz², Magnólia de Jesus Sousa Magalhães Assunção ${ }^{1}$.

${ }^{1}$ Centro Universitário de Ciências e Tecnologia do maranhão-UNIFACEMA, Departamento de Nutrição, Instituição de Ensino Superior, Caxias-MA, Brasil.

${ }^{2}$ Universidade Federal do Piauí-UFPI, Departamento de Nutrição, Instituição de Ensino Superior, Teresina-PI, Brasil.

*Correspondência: Centro Universitário de Ciências e Tecnologia do maranhão-UNIFACEMA, R. Aarão Réis, 1036-1136 - Centro, Caxias, Maranhão, Brasil.CEP: 65604-010.E-mail: joycelopes385@gmail.com.

\section{Artigo recebido em 08/01/2019 aprovado em 20/03/2020 publicado em 26/03/2020.}

\section{RESUMO}

Ao passar dos anos as Unidades de Alimentação e Nutrição (UAN) têm crescido significativamente, todavia, muitas apresentam padrões de estruturas físicas e funcionais inadequadas. A pesquisa teve por objetivo analisar a adequação da estrutura física e funcional de uma UAN em um município Maranhense. Estudo descritivo e transversal, utilizando como critério a RDC $\mathrm{n}^{\circ} 275$ de 2002, para determinar se as condições estruturais e funcionais encontravam-se em situações propícias à obtenção de alimentos seguros. As opções de respostas para o preenchimento do checklist foram: para conforme (C), itens não conforme (NC), para os itens não atendidos, e não se aplica (NA), aos itens observados no estabelecimento avaliado. Verificou-se algumas falhas quanto à estrutura física, aspectos como iluminação, ventilação, pisos e paredes, portas e janelas, bem como instalações elétricas, hidráulicas e de gás apresentaram-se inadequadas, em relação a estrutura funcional, observou-se condições insatisfatórias relacionadas ao destino do lixo, contudo, o controle da potabilidade de água, pragas e vetores estavam adequadas, a referida unidade possui registros, manuais, fichas técnicas e demais formas de controle para a padronização e funcionamento da UAN. Conclui-se que a unidade se encontra em condições inadequadas, indicando a necessidade de mudanças que visem à sua melhoria.

Palavras-chave: Unidade de Alimentação e Nutrição. Estrutura Física. Estrutura Funcional.

\section{ABSTRACT}

Over the years the Food and Nutrition Units (UAN) have grown significantly; however, many have inadequate physical and functional patterns. The aim of the research was to analyze the adequacy of the physical and functional structure of a UAN in a municipality of Maranhense. Descriptive and cross-sectional study, using RDC No. 275 of 2002, to determine if the structural and functional conditions were in situations conducive to obtaining safe food. The response options for completing the checklist were: according to $(C)$, items not conforming $(N C)$, for items not met, and not applicable (NA), to items observed at the evaluated establishment. There were some flaws in the physical structure, aspects such as lighting, ventilation, floors and walls, doors and windows, as well as electrical, hydraulic and gas installations were inadequate, in relation to the functional structure, unsatisfactory related conditions to the destination of the waste, however, the control of the potability of water, pests and vectors were adequate, this unit 
has records, manuals, technical sheets and other forms of control for the standardization and operation of UAN. It is concluded that the unit is in inadequate conditions, indicating the need for changes aimed at its improvement.

Keywords: Food and Nutrition Unit. Physical structure. Functional Structure.

\section{RESUMEN}

Al pasar de los años las Unidades de Alimentación y Nutrición (UAN) han crecido significativamente, sin embargo, muchas presentan patrones de estructuras físicas y funcionales inadecuadas. La investigación tuvo por objetivo analizar la adecuación de la estructura física y funcional de una UAN en un municipio Maranhense. Estudio descriptivo y transversal, utilizando como criterio la RDC $n^{\circ} 275$ de 2002, para determinar si las condiciones estructurales y funcionales se encontraban en situaciones propicias para la obtención de alimentos seguros. Las opciones de respuesta para el llenado del checklist fueron: para conforme (C), items no conforme (NC), para los items no atendidos, y no se aplica (NA), a los ítems observados en el establecimiento evaluado. Se verificaron algunas fallas en cuanto a la estructura física, aspectos como iluminación, ventilación, pisos y paredes, puertas y ventanas, así como instalaciones eléctricas, hidráulicas y de gas se presentaron inadecuadas, en relación a la estructura funcional, se observaron condiciones insatisfactorias relacionadas a la llegada de la basura, sin embargo, el control de la potabilidad de agua, plagas y vectores eran adecuados, dicha unidad posee registros, manuales, fichas técnicas y demás formas de control para la estandarización y funcionamiento de la UAN. Se concluye que la unidad se encuentra en condiciones inadecuadas, indicando la necesidad de cambios que apunte a su mejora.

Descriptores: Unidad de Alimentación y Nutrición. Estructura física. Estructura funcional.

\section{INTRODUÇÃO}

O mercado de alimentação, de acordo com Abreu, Spinelli e Pinto (2009), é dividido em alimentação coletiva, sendo que os estabelecimentos que trabalham com produção e distribuição de alimentos para coletividades, atualmente recebem o nome de Unidades de Alimentação e Nutrição (UANs).

Segundo Teixeira, Oliveira e Rego (2006), Unidade de Alimentação e Nutrição é uma unidade de trabalho ou órgão de uma empresa, que desempenha atividades relacionadas à alimentação e nutrição, independentemente da situação que ocupa na escala hierárquica da entidade, seja no nível de divisão, seção, setor, etc.

Dentro da UAN é necessário satisfazer o cliente tanto por aspectos tangíveis (cardápio, apresentação e aspectos físicos) como intangíveis (expectativas, percepções e ambiente) da qualidade. A somatória desses aspectos resulta na qualidade total do atendimento e/ou produto, o qual busca não somente satisfazer o desejo do cliente, mas sim atingir suas expectativas (ABREU; SPINELLI; PINTO, 2011).
A análise da estrutura física e funcional de uma UAN é de fundamental importância para que se possam determinar as ações a serem tomadas e, assim, evitar eventuais desperdícios e problemas operacionais nas atividades realizadas (GUIMARÃES, 2006).

E para ter um bom planejamento é essencial um layout, definido como uma imagem vista de cima, que ordena onde tudo deve ficar bem colocado, feito para aperfeiçoar todos os processos, buscando uma melhoria, minimização os custos e aumentando a satisfação do cliente. Um layout também é muito importante para uma alta produtividade. $\mathrm{O}$ objetivo de um layout é fazer com que o consumidor, sendo de qualquer classe econômica, e gosto de próprio, se sinta à vontade. O layout pode modificar a pratica de um espaço, e certificar o conforto e satisfação dos clientes e melhorar as vendas (CARNEIRO; VENANTE; LEITE, 2015).

Diante do que foi exposto, a pesquisa teve por objetivo analisar a adequação da estrutura física e funcional de uma UAN em um município Maranhense. 


\section{MATERIAIS E MÉTODOS}

O presente estudo caracteriza-se por ser descritivo e de corte transversal.

A presente pesquisa foi desenvolvida em uma Unidade de Alimentação e Nutrição (UAN) hospitalar, de um município do estado do Maranhão, durante o primeiro semestre de 2018, tendo como objetivo verificar as condições físicas e funcionais do local.

Para a avaliação, utilizou-se uma lista de verificação, adaptada da RDC n 275 , de2002, sendo utilizado, para classificação do estabelecimento um checklist, com as seguintes opções de resposta: para itens conforme $(\mathrm{C})$, itens não conforme $(\mathrm{NC})$, para os itens não atendidos, e não se aplica (NA), aos itens observados no estabelecimento avaliado.

Observou-se também, se a unidade segue as exigências da legislação vigente, no que diz respeito à

aplicação do Manual de Boas Práticas e dos Procedimentos Operacionais Padronizados (POP's).

\section{RESULTADOS E DISCUSSÃO}

O planejamento físico de uma UAN é essencial tanto na questão econômica, como na funcionalidade da cozinha, evita cruzamentos desnecessários de gêneros alimentícios e funcionários; má utilização de equipamentos; localização desapropriada e falta de ventilação (TEIXEIRA; OLIVEIRA, REGO, 2004).

$\mathrm{Na}$ referida UAN é possível observar as seguintes áreas: refeitório, banheiro masculino, banheiro feminino, vestiário, dispensa de descartáveis, dispensa de gêneros não perecíveis, dispensa de gêneros perecíveis, sala da nutricionista, sala da auxiliar de nutrição, área de higienização, área de preparo de lanches, área de preparo e cocção (Figura $1)$.

Figura 1. Layout da Unidade de Alimentação e Nutrição hospitalar de um município do Maranhão.

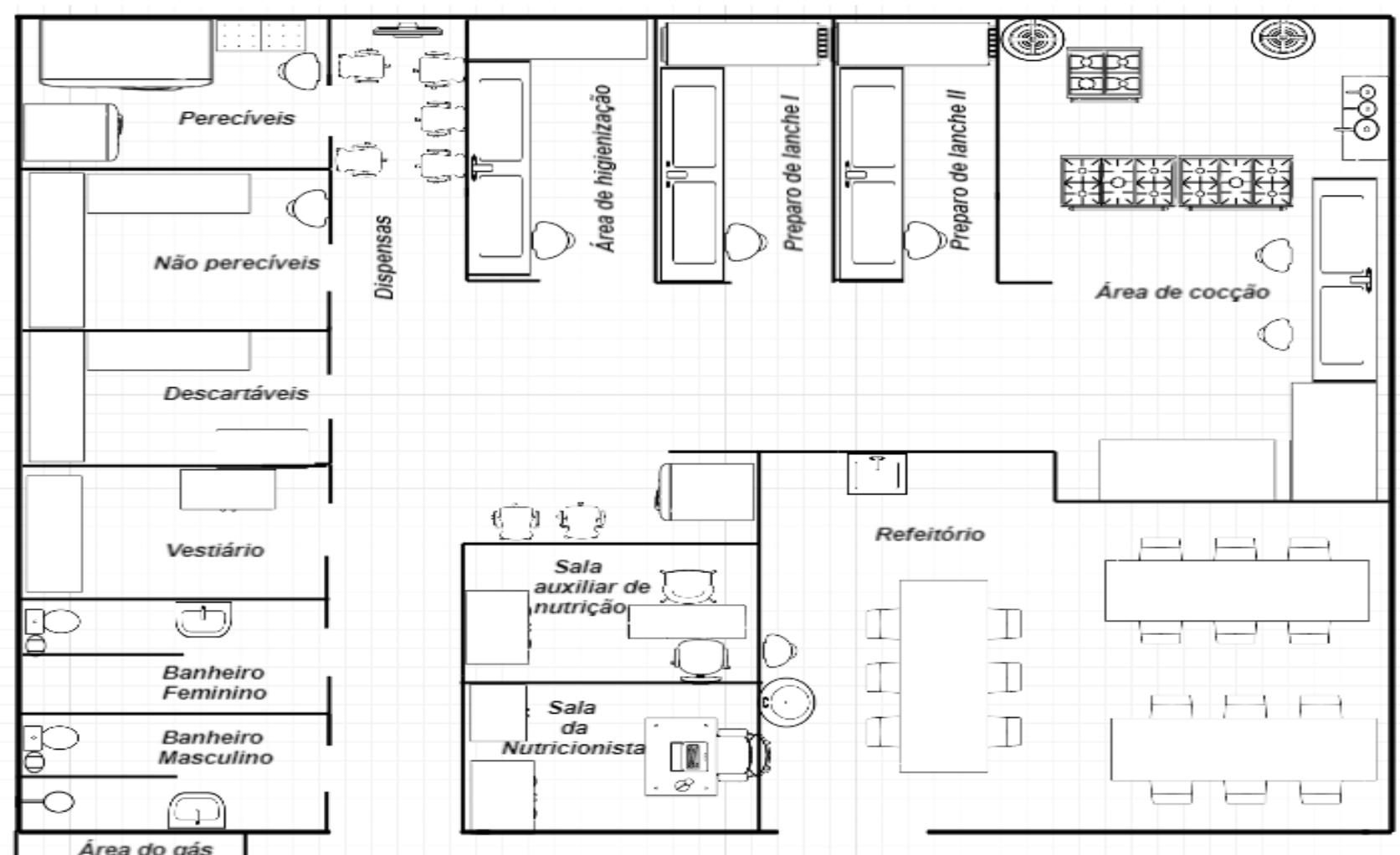

Fonte: Dados da pesquisa, 2018. 
A estrutura física da UAN, contem banheiros na parte interna que integra a estrutura, onde de acordo com Guimarães (2006), os banheiros devem ser separados por sexo e em bom estado de conservação, constituído de vaso sanitário, pia, mictório (masculino) e chuveiro para cada 20 funcionários, pias para lavar as mãos com torneiras de acionamento automático e armários individuais. As instalações sanitárias não devem se comunicar diretamente com a área de manipulação de alimentos ou refeitórios.

A forma retangular é a configuração geométrica recomendada para Unidades de Alimentação e Nutrição porque reduz caminhada desnecessária e favorece a melhora do fluxo de produção. Além do fato de que as instalações adequadas asseguram a qualidade da produção do serviço prestado. É recomendável que a localização do serviço de alimentação seja no andar térreo, permitindo melhor operacionalização, facilitando a iluminação e ventilação natural, contribuindo para a remoção do lixo, que pode acarretar sérios riscos de contaminação pelo odor, proliferação de microrganismos e diferentes tipos de vetores (MEZOMO, 2006).

Na tabela 1 observa-se o dimensionamento da área física da Unidade de Alimentação e Nutrição.

Tabela 1. Dimensionamento da área da Unidade de Alimentação e Nutrição hospitalar de um município do Maranhão.

\begin{tabular}{cccc}
\hline Área & Comprimento $(\mathbf{m})$ & Largura $(\mathbf{m})$ & Dimensão $\left(\mathbf{m}^{\mathbf{2}}\right)$ \\
\hline Refeitório & 8,73 & 8,20 & 71,58 \\
\hline Banheiro Masculino & 2,93 & 2,0 & 5,86 \\
\hline Banheiro Feminino & 2,93 & 2,0 & 5,86 \\
\hline Sala da Nutricionista & 3,40 & 3,07 & 10,43 \\
\hline Vestiário & 2,93 & 1,23 & 3,60 \\
\hline Área de descartáveis & 2,93 & 2,02 & 5,91 \\
\hline Sala de auxiliar de nutrição & 3,07 & 3,40 & 10,43 \\
\hline Dispensa não perecíveis & 2,93 & 2,40 & 7,03 \\
\hline Dispensa perecíveis & 3,07 & 2,56 & 7,85 \\
\hline Higienização & 3,50 & 2,22 & 7,77 \\
\hline Preparo de lanche 1 & 3,50 & 2,22 & 7,77 \\
\hline Preparo de lanche 2 & 3,50 & 2,22 & 7,77 \\
\hline Área de cocção & 7,30 & 5,68 & 193,46 \\
\hline Total & & & \\
\hline
\end{tabular}

Fonte: Dados da pesquisa, 2018

A UAN em estudo está localizada no andar térreo, possuí uma área geométrica retangular com pouca iluminação natural, em bloco isolado. necessita de melhorias organizacionais para melhor qualidade dos serviços realizados no local e conforto para os funcionários.

A ventilação, a temperatura e a umidade estão implicitamente interligadas. Segundo Teixeira (2004) a ventilação deve ser adequada para propiciar a renovação do ar, garantindo o conforto térmico. A circulação do ar deve ser assegurada por meios naturais ou por equipamentos devidamente direcionados, não sendo permitido uso de ventiladores nas áreas de processamento e manipulação de alimentos.

Uma temperatura de $22^{\circ}$ a $26^{\circ}$, com umidade relativa de 50 a $60 \%$ é considerada compatível com as operações realizadas em uma UAN. Outros fatores 
podem contribuir para amenizar o calor, como o modelo de fardamento, tipo e cor dos tecidos, etc. o fardamento é um aspecto muito importante, na medida em que pode comprometer a produtividade e o padrão higiênico das refeições, pela possibilidade de favorecer a proliferação de bactérias, em temperatura de $28^{\circ}$ a $37^{\circ}$, e pela sudorese que acomete os funcionários (MEZOMO, 2006).

Sendo assim observou-se que em relação aos aspectos físicos, em particular o quesito da ventilação, a UAN encontra-se em situação precária, pois não garante certo grau de conforto térmico para os colaboradores, precisamente pelo fato de não ter abertura nas paredes que permitam a circulação natural do ar.

De acordo com Brasil (2004), a iluminação da área de preparação deve proporcionar a visualização de forma que as atividades sejam realizadas sem comprometer a higiene e as características sensoriais dos alimentos. As luminárias localizadas sobre a área de preparação dos alimentos devem ser apropriadas e estar protegidas contra explosões e quedas acidentais.

A iluminação mais recomendada para as UANs, é a natural que, sendo um acelerador das trocas orgânicas, funciona como bactericida, devido a existência de raios ultravioletas. A iluminação natural estimula as funções do organismo, propiciando sensações de alegria e maior disposição para o trabalho, está diretamente relacionada ao nível de trabalho produzido. Além disso, a iluminação natural é mais econômica, vez que é obtida da luz solar e pode ser assegurada ao ambiente de trabalho, através de aberturas equivalentes de $1 / 5$ a $1 / 4$ da área do piso projetada (MEZOMO, 2006).

No entanto, a iluminação observada, em relação aos aspectos físicos, encontra-se em situação precária, pois não é natural, não possui proteção e nem tão pouco é distribuída uniformemente pelo ambiente, o que pode ocasionar ofuscamentos, sombras, reflexos fortes e contrastes excessivos.

As escolhas do revestimento para o piso, assim como sua aplicação, devem merecer atenção especial e corresponder às exigências técnicas, que variam conforme a natureza do trabalho a ser executado e o esforço a que serão submetidos os materiais aplicados. A aplicação do piso monolítico é um fator que favorece a higienização, pois os rejuntes dos pisos de cerâmica, por serem de cimento, são porosos, dificultando a higienização e favorecendo a proliferação de bactérias. No que diz respeito à cor, o seu índice de reflexão deve estar situado entre 15 e $30 \%$. Além disso, o piso deve ter um único nível, evitando os acidentes de trabalho e favorecendo o deslocamento de carros, também devem ter inclinação suficiente para direcionar, aos ralos, a água de higienização (TEIXEIRA, 2007).

Em relação ao piso da UAN em estudo, observou-se que o mesmo não é antiderrapante, o que pode dificultar a funcionalidade dentro da UAN, observou-se ainda que o próprio apresenta cantos arredondados, sendo composto de monobloco com pouco rejunte o que facilita a higienização.

Conforme ABERC (2009), o teto e forro devem apresentar-se em bom estado de conservação, isentos de trincas, rachaduras, umidade, bolor $\mathrm{e}$ descascamentos, com acabamento liso, impermeável, lavável e em cor clara.

No que diz respeito ao teto da UAN estudada, o forro é feito de PVC, não sendo de fácil higienização e não lavável, além de ser muito baixo, dificultando a ventilação, apresentando ainda pragas e vetores.

As paredes e divisórias também devem ser de cores claras, com acabamento liso, possuindo características duráveis e impermeáveis, resistentes a limpezas frequentes, livres de fungos e bolores (ABERC, 2009). 
De acordo com o que foi observado na UAN, as paredes se encontram revestidas de azulejos até o teto, de cor clara que facilita a higienização, mas apresenta rejunte espaçoso o que possibilita o acumulo de sujeira, pois de acordo com a literatura o mesmo deve ter o mínimo de espaço possível.

As portas e janelas devem ser mantidas ajustadas aos batentes. As portas da área de preparação e armazenamento de alimentos devem possuir fechamento automático. As aberturas externas das áreas de armazenamento e preparação de alimentos, inclusive o sistema de exaustão, devem ser providas de telas milimétricas para impedir o acesso de vetores e pragas urbanas. As telas devem ser removíveis para facilitar a limpeza periódica.

Desta forma de acordo com o que foi observado no estudo, as janelas da UAN não apresentam telas milimétricas, bem como as portas não possuem vedação e fechamento automático.

Teixeira (2004) considera como instalações todas as redes elétricas, hidráulica, de vapor, de emergência e outras que proporcionam boa infraestrutura à UAN. Todas elas devem possuir a devida identificação. Brasil (2004) menciona que as instalações elétricas devem estar embutidas ou protegidas em tubulações externas e íntegras de tal forma a permitir a higienização dos ambientes.

É recomendável que as tubulações sejam externas, para facilitar a manutenção. Atenção especial deve ser dispensada à escolha das tomadas de força, que devem ser individualizadas para cada equipamento, além disso, recomenda-se também que estas tomadas sejam do tipo blindado, para facilitar a higienização das paredes e evitar a entrada de água na rede elétrica, que pode ocasionar acidente de trabalho ou danos aos equipamentos (TEIXEIRA et al., 2007).

As instalações elétricas da UAN, apresentamse de forma inadequadas pois encontram-se expostas, apresentando riscos para os colaboradores da Unidade de Alimentação e Nutrição.

A água que abastece o local, recebe tratamento de empresas terceirizadas, o que de acordo com informações locais é suficiente para garantir sua potabilidade. As instalações do esgoto são encanadas e internas, não apresentam contem, onde a drenagem da água ocorre através de ralos que não são sifonados com tampas removíveis distribuídos por toda UAN. A evacuação da água é feita através da rede pública de esgotos.

A área do gás localiza-se bem perto da UAN, é coberta, mas não se encontra isolada por um portão, além disto, contém vários objetos em desuso.

Os aspectos físico-funcionais precisam ser considerados na fase de preparação do projeto de implantação da UAN, pois intervêm na segurança dos alimentos e podem danificar o funcionamento correto do serviço de alimentação (SOARES, 2010).

Cruz et al (2006) afirmam que a qualidade da água é de fundamental importância, já que a mesma é considerada um veículo para muitos microrganismos patogênicos.

Segundo a RDC $\mathrm{N}^{\circ} 216$, deve ser utilizada somente água potável para manipulação de alimentos. Quando utilizada solução alternativa de abastecimento de água, a potabilidade deve ser atestada semestralmente mediante laudos laboratoriais, sem prejuízo de outras exigências previstas em legislação específica.

O controle da potabilidade da água é feito por meio da rede de Serviço Autônomo de Água e Esgoto (SAAE), e é recolhida amostra da água para controle.

No procedimento para um correto descarte do lixo deve ser realizado uma rotina, para manter o local constantemente limpo, desinfetado e organizado; manter o local de armazenamento do lixo tampado; a coleta deve ser feita diariamente por empresa especializada ou pessoa autorizada; não permitir que 
os sacos fiquem cheios a ponto de impossibilitar que os mesmos sejam amarrados; condução dos resíduos até a área do descarte por caminho onde não haja cruzamento com o fluxo da produção da unidade (ARRUDA, 2002).

Observou-se que no local de estudo, não há separação de lixo orgânico e lixo hospitalar, e nem local refrigerado, a saída do lixo é feita pelo mesmo local onde entram as matérias-primas, proporcionando uma possível contaminação cruzada. No entanto, vale ressaltar que a edificação e as instalações devem ser projetadas de forma a possibilitar um fluxo ordenado e sem cruzamentos em todas as etapas da preparação de alimentos e a facilitar as operações (BRASIL, 2004).

As instalações, os equipamentos, os móveis e os utensílios da UAN não são isentos de vetores e pragas urbanas, e o controle é feito pela prefeitura do município, a cada três meses, estando de acordo com a RDC $n^{\circ} .216$ de 15 de setembro de 2004 (BRASIL, 2004).

Em estudo desenvolvido por Cruz et al (2006), constatou-se que o controle de pragas em uma unidade elaboradora de alimentos mostrava-se totalmente inexistente, podendo realmente ocasionar prejuízos para a segurança microbiológica das refeições a serem servidas, dados iguais foram verificados na UAN.

A RDC no. 216 de 15 de setembro de 2004 constitui que devem ser inseridos procedimentos enérgicos e contínuos de modo a prevenir ou minimizar a presença de vetores e pragas urbanas em Unidades de Alimentação e Nutrição (BRASIL, 2004).

Para uma Unidade de Alimentação e Nutrição (UAN) é necessário manter o controle higiênico sanitário eficiente para seguir as leis estabelecidas pela Agência Nacional de Vigilância Sanitária (ANVISA). Um dos instrumentos para a qualidade é a elaboração e implantação do Manual de Boas Práticas (MBP) que é fundamental para a produção de alimentos com qualidade, tanto do ponto de vista nutricional quanto em relação à segurança alimentar para os consumidores (ANVISA, 2004).

Foi observado que há formas de uniformização para uma melhor funcionalidade da UAN, em se tratando de manual de boas práticas de fabricação (MBPF), métodos operacionais padronizados (POPs).

Entretanto, é preciso orientar os manipuladores sobre os cuidados na obtenção, acondicionamento, manipulação, conservação e exposição à vendados alimentos, bem como a estrutura física do local de manipulação para que a qualidade sanitária do alimento não esteja em risco pelos perigos químicos, físicos e biológicos. Desse modo, as Boas Práticas de Manipulação são regras que, quando praticadas, ajudam a evitar ou reduzir os perigos ou contaminação de alimentos (FORSYTHE, 2005).

Para evitar os problemas de saúde causados pela falta de cuidado com os alimentos, criou-se a Resolução de Diretoria Colegiada (RDC) $n^{\circ}$ 216/04 que tem como objetivo constituir procedimentos de Boas Práticas para serviços de alimentação a fim de garantir as condições higiênico-sanitárias do alimento preparado. Os prérequisitos para uma unidade de serviço de alimentação compreendem os seguintes aspectos: instalações, edificação, moveis e utensílios equipamentos, controle de vetores e pragas urbanas, abastecimento de água, manejo de resíduos, higiene e saúde dos manipuladores, matérias primas, ingredientes $\mathrm{e}$ embalagens, preparação do alimento, armazenamento e transporte do alimento preparado, exposição ao consumo do alimento preparado (ABREU; SPINELLI; PINTO, 2011).

As práticas impróprias que ocorrem durante o processamento do alimento podem facilitar a contaminação, a sobrevivência e a multiplicação de micro-organismos causadores de Doenças Transmitidas por Alimentos (DTA). A informação dos 
principais pontos de contaminação durante o preparo dos alimentos é essencial para atribuir qualidade microbiológica e segurança para o consumidor. As Boas Práticas de Higiene e Manipulação e educação continuada dos manipuladores de alimentos contribuem para a redução da incidência de intoxicações de origem alimentar (FRANCO; LANDGRAF, 2008)

Observou -se que a UAN não possui fichas técnicas de preparação. E sabe-se que a forma mais eficiente para a padronização e controle de qualidade é a elaboração das Fichas Técnicas de Preparação (FTP). São recursos utilizados para garantir que uma mesma preparação seja fornecida com a mesma qualidade e características sensoriais, independente de quem tenha preparado. A adoção das FTP facilita a integração e treinamento de novos funcionários na execução das preparações e padroniza o sistema de produção garantindo que o produto final tenha sempre composição, valor nutritivo e apresentação semelhantes (ABREU.; SPINELLI.; PINTO, 2009).

Portanto, o projeto físico-funcional tem como objetivo fundamental garantir instalações apropriadas e funcionais, garantindo as operacionalizações dentro das mais rigorosas normas técnicas de higiene, bem como a característica da produção do serviço prestado aos comensais. Este planejamento envolve um enfoque apropriado de uma série de aspectos principais, como: localização e configuração geométrica da UAN, determinação e dimensionamento das áreas de trabalho, e dimensionamento correspondente à distribuição dos equipamentos de acordo com o fluxo.

\section{CONCLUSÃO}

O presente estudo revelou diversas inadequações físico-funcionais, especialmente em relação à estrutura física.

Observou-se que a estrutura foi adaptada para o funcionamento e não planejada conforme indicado pelas resoluções existentes. Essas irregularidades comprometem as condições higiênico-sanitárias do alimento e influenciam na qualidade do trabalho.

Através dos resultados encontrados é possível traçar medidas corretivas, realizar adequações necessárias e perceber a importância de cada recomendação e o quanto cada aspecto interfere do produto final oferecido e na ambiência da UAN.

Sugere-se para outros estudos a realização com maior número de UANs, para possibilidade de comparação de resultados e aplicação da lista de verificação a fim, de investigar, avaliar e comparar a situação em que se encontram as UANs e possibilitar criação de melhorias para as inadequações encontradas que influenciam diretamente na execução da rotina de atividades.

Todos os autores declararam não haver qualquer potencial conflito de interesses referente a este artigo.

\section{REFERÊNCIAS}

ABERC - Associação Brasileira das Empresas de Refeições Coletivas. Manual dePráticas de elaboração e serviço para coletividade. 8 ed. São Paulo: ABERC,2009.

ABREU, E. S.; SPINELLI, M. G. N.; PINTO, A. M. S. Gestão de unidades de alimentação e nutrição: um modo de fazer. 3. ed. São Paulo: Metha, 2009.

ABREU, E.S.; SPINELLI, M.G.N.; PINTO, A.M.S. Gestão de Unidades de Alimentação e Nutrição: um modo de fazer. $4^{\mathrm{a}}$ ed. São Paulo: Editora Metha, 2011.

ANVISA. Cartilha sobre Boas Práticas para Serviços de Alimentação -Resolução nº 216/2004.

ARRUDA, G. A. Manual de Boas Práticas: Unidades de Alimentação e Nutrição. 2. ed. São Paulo: Ponto Crítico. p. 234- 236, 2002.

BRASIL. Ministério do Trabalho e Emprego. Avaliação do PAT. Brasília, DF, 2004.

CARNEIRO, P.; VENANTE, B.; LEITE, D. G. Avaliação de Layout de uma Unidade de Alimentação e Nutrição em um hotel da cidade de Piraí do Sul. FACULDADES PONTA GROSSA. v. 1 n. 2, 2015. 
CRUZ, A. G.; CENCI, S. A.; MAIA, M. C. A. Prérequisitos para implementação do sistema APPCC em uma linha de alface minimamente processada. Ciência e Tecnologia de Alimentos., São Paulo, v. 26, n. 1, p. 104-109, 2006

FORSYTHE. Microbiologia da Segurança Alimentar. Porto Alegre: Artmed, 2005.

FRANCO, B.D.G. M.; LANDGRAF, M. Microbiologia dos Alimentos. São Paulo: Atheneu, 2008.

GUIMARÃES, I. A. A análise da estrutura física e funcional de uma UAN é de fundamental importância para que se possam determinar as ações a serem tomadas e assim evitar eventuais desperdícios e problemas operacionais. Dissertação (Mestrado) Universidade de Brasília, Centro de Excelência em Turismo, Brasília, 2006.

MEZOMO, I. F. B. Os serviços de Alimentação: Planejamento e Administrção.5 ed. Manole: São Paulo, 2006.
SOARES, A. V. S. Avaliação do serviço de alimentação e nutrição oferecido pelo restaurante popular herbert de Sousa, 2010. TEIXEIRA, S. M. F. G.; OLIVEIRA, Z. M. C.; REGO, J. C. Administração aplicada às unidades de alimentação e nutrição. São Paulo: Atheneu, 2006. 